\title{
Irregularidade da posse da terra urbana, invasáo de domicílios e espaço metropolitano
}

Frederico Ferreira. Fundação João Pinheiro, Belo Horizonte, Brasil.

RESUMO | Tendo por base vertentes teóricas que procuram vincular o comportamento criminoso ao espaço e utilizando dados da Pesquisa por Amostra de Domicílios do Estado de Minas Gerais, Brasil -2013, foi possível, a partir de uma análise Loglinear, cruzar informaçóes sobre a irregularidade da posse da terra urbana na Região Metropolitana de Belo Horizonte, com o fato do domicílio ter sido invadido pelo menos uma vez. Os resultados indicam uma correlação positiva entre irregularidade da propriedade da terra e arrombamentos, nos municípios da região metropolitana e ao contrário, uma relação negativa no município de Belo Horizonte. Entre as explicaçóes aventadas, estaria o fato de que na capital as áreas irregulares, já mais consolidadas, teriam maior coesão social, o que lhes garantiriam maior segurança, inclusive, da posse da terra. Fato que não seria observado em áreas de ocupação mais recente e que, mais frequentemente, surgem no restante da região metropolitana.

PALAVRAS-CHAVE | habitação, integração social, violência.

ABSTRACT | Based on theoretical frameworks that seek to link criminal behavior to space and using data from Household Sample Survey of the State of Minas Gerais, Brazil-2013, we developed a Loglinear analysis with information about the insecurity of urban land tenure in the Metropolitan Region of Belo Horizonte. This analysis also examines the fact of whether a household, in this area, was invaded at least once or not. The results show both a positive correlation between insecure land tenure and house invasion in the municipalities of the metropolitan region as well as a negative correlation in Belo Horizonte. Among the explanations, we noted that in the capital the already consolidated irregular areas, would have greater social cohesion. This would also guarantee them greater housing security, even of the land tenure. This aspect would not be observed in areas of recent occupation that are more common in the metropolitan periphery.

KEYWORDs | housing, social integration, violence. 


\section{Introduçáo}

O principal objetivo desse trabalho é procurar entender algumas relaçóes entre a irregularidade da propriedade do solo urbano por parte dos domicílios, localizados na Região Metropolitana de Belo Horizonte, no Estado de Minas Gerais, Brasil e o crime definido como invasão e ou arrombamento de domicílios. Num primeiro momento procuramos aventar a hipótese de que os domicílios com irregularidades da posse, estariam mais sujeitos a esse tipo de violência. As relaçóes de propriedade poderiam enfraquecer ou fortalecer a própria segurança da posse e consequentemente da proteção do domicílio, contra invasóes e arrombamentos.

Essa análise só foi possível a partir da Pesquisa de Amostra de Domicílios de Minas Gerais (PAD MG) 2013 (FJP, 2014), que de forma inédita no Brasil, reuniu em um mesmo banco de dados questóes relativas à posse da terra e também quanto a segurança pública numa perspectiva domiciliar.

Esse trabalho tem características eminentemente exploratórias. Não se procura desenvolver os determinantes ou se discutir as causas da criminalidade contra o patrimônio de forma estrita. Também não será abordado o que leva à irregularidade da posse da terra urbana (em ambos os casos há uma vasta e complexa literatura disponível).

Porém, procurou-se identificar e analisar alguns aspectos relativos às intercessôes de determinados conceitos do desenvolvimento urbano e da habitação, com algumas teorias sociais e da segurança pública, mais especificamente, aquelas que lidam de forma mais direta com variáveis geográficas, ou relativas às características do espaço urbano (ecológicas) e da localização dos domicílios.

No Brasil, historicamente nas cidades, as classes mais pobres tendem a ocupar os espaços mais distantes e menos valorizados ao centro urbano que, normalmente, é mais dotado de infraestrutura e serviços. Esse padrão parece não ter se alterado completamente nas últimas décadas, mesmo estando ocorrendo, nessas áreas, um processo de rápido envelhecimento populacional, arrefecimento das taxas de crescimento, (basicamente, devido à queda da fecundidade e à redução dos fluxos migratórios, em especial o rural - urbano) e o surgimento dos condomínios de alta renda também em regiôes mais distantes às áreas mais centrais (Abramo, 2003; Canettieri, 2014; Souza, 2008; Villaça, 2001).

Dessa maneira, pode-se observar na tabela 1, que mesmo existindo uma expressiva redução de todas as taxas anuais de crescimento populacional na Regiáo Metropolitana, principalmente entre 1970 e 2010, o município de Belo Horizonte apresenta taxas menores que o restante da regiáo, sendo que, sua participação relativa no total populacional regional vem decrescendo continuamente, alcançando por volta de $44 \%$ do contingente total, no ano de 2010 . Por sua vez, é possível constatar pela tabela 2 que as maiores densidades populacionais também estão aí concentradas (Belo Horizonte já não possui áreas livres e disponíveis de expansão urbana, sendo que seu crescimento se dá, fundamentalmente, via aumento do adensamento). Além disso, a capital também concentra a maior parte dos empregos, da renda, (o que pode ser constatado pelo seu elevado PIB per capita), a melhor infraestrutura 
urbana, além dos domicílios com maior renda média. Esse padrão, como já observado, ainda é prevalente.

Assim, de acordo com Canettierri (2014): "O que se observa no contexto analisado entre os anos de 2000 e 2010 para a RMBH é a tendência, que se reforça, de a pobreza se localizar nas áreas periféricas. Essa periferização da pobreza é acompanhada pelo espraiamento do espaço construído e passa a ter uma forma fractal” (p. 219).

Grande parte desses novos espaços que vão sendo ocupados nas áreas mais distantes ao centro metropolitano reproduzem os vários e já bem descritos processos de exclusão espacial entre eles o da própria irregularidade nas formas de ocupação das terras. Normalmente, essas áreas urbanas informais e empobrecidas tendem a contratar com as áreas formais e economicamente dinâmicas. De acordo com Ávila e Ferreira (2016):

Quando se trata da irregularidade fundiária no Brasil, normalmente vem à mente as imagens das favelas e dos parcelamentos de solo irregulares e/ou clandestinos. Talvez, a mais marcante ainda seja a imagem das favelas, que afetam fortemente a paisagem das áreas metropolitanas do país, ao estabelecer um forte contraste aos olhos de estudiosos e do público em geral. Esse contraste se estabelece a partir da observação lado a lado de uma cidade legal - planejada, organizada e estruturada segundo um arsenal de leis e normas urbanísticas - e outra ilegal - espaço contingente e anárquico em que se sobrepóem, de maneira contundente, a desorganização do ambiente físico, problemas de ordem social e econômica. (p. 198)

TABELA I | Belo Horizonte e outros municípios da Região Metropolitana de Belo Horizonte (Rмвн) População e Taxa Geométrica de Crescimento (1940-2010)

\begin{tabular}{|c|c|c|c|c|c|c|c|c|c|}
\hline \multirow[t]{2}{*}{ ANO } & \multicolumn{3}{|c|}{ POPULAÇÃO (MIL) } & \multicolumn{3}{|c|}{ TAXA DE CRESCIMENTO** } & \multicolumn{3}{|c|}{$\begin{array}{c}\text { PARTICIPAÇÃO (\%) NA } \\
\text { RMBH }\end{array}$} \\
\hline & BH & $\begin{array}{l}\text { OUTROS } \\
\text { RMBH* }^{*}\end{array}$ & RMBH & BH & $\begin{array}{l}\text { OUTROS } \\
\text { RMBH* }\end{array}$ & RMBH & BH & $\begin{array}{l}\text { OUTROS } \\
\text { RMBH* }^{*}\end{array}$ & RMBH \\
\hline 1940 & 211,377 & 157,41 & 368,78 & & & & 57,32 & 42,68 & $100 \%$ \\
\hline 1950 & 352,724 & 170,19 & 522,92 & 5,25 & 0,78 & 3,55 & 67,455 & 32,55 & $100 \%$ \\
\hline 1960 & 693,328 & 237,96 & 931,28 & 6,99 & 3,41 & 5,94 & 74,45 & 25,55 & $100 \%$ \\
\hline 1970 & $1.235,03$ & 484,46 & $1.719,49$ & 5,94 & 7,37 & 6,32 & 71,83 & 28,17 & $100 \%$ \\
\hline 1980 & $1.780,84$ & 895,54 & $2.676,38$ & 3,73 & 6,34 & 4,52 & 66,54 & 33,46 & $100 \%$ \\
\hline 1991 & $2.020,16$ & $1.503,75$ & $3.523,91$ & 1,15 & 4,82 & 2,53 & 57,33 & 42,67 & $100 \%$ \\
\hline 2000 & $2.238,53$ & $2.580,76$ & $4.819,29$ & 1,15 & 6,19 & 3,54 & 46,44 & 53,56 & $100 \%$ \\
\hline 2010 & $2.375,15$ & $3.039,55$ & $5.414,70$ & 0,59 & 1,65 & 1,17 & 43,86 & 56,14 & $100 \%$ \\
\hline \multicolumn{10}{|c|}{$\begin{array}{l}\text { DEMAIS MUNICÍPIOS DA REGIÃO METROPOLITANA DE BELO HORIZONTE, EXCLUINDO-SE BELO } \\
\text { HORIZONTE }\end{array}$} \\
\hline FONTE & \multicolumn{9}{|c|}{$\begin{array}{l}\text { TAXA GEOMÉTRICA DE CRESCIMENTO POPULACIONAL ANUAL ENTRE O RESPECTIVO ANO E O } \\
\text { IMEDIATAMENTE ANTERIOR }\end{array}$} \\
\hline FONTE & \multicolumn{9}{|c|}{ ELABORAÇÃO PRÓPRIA COM BASE EM IBGE (20IO) } \\
\hline
\end{tabular}


TABELA 2 Densidade populacional 2010 e PIB per-capita 2013, Belo Horizonte e Regiáo Metropolitana

\begin{tabular}{|l|c|c|}
\hline \multicolumn{1}{|c|}{ LOCAL } & DENSIDADE POP 2OIO/KM & PIB20I3/POP 20IO R\$ \\
\hline BH & $7.167,0$ & $34.282,76$ \\
\hline Outros RMBH* & 332,54 & $27.737,59$ \\
\hline RMBH & 571,67 & $30.608,62$ \\
\hline
\end{tabular}

DEMAIS MUNICÍPIOS DA REGIÃO METROPOLITANA DE BELO HORIZONTE, EXCLUINDO-SE BELO HORIZONTE

FONTE ELABORAÇÃo PRÓPRIA COM BASE EM IBGE (2OIO) E FJP (20I6)

\section{A irregularidade da propriedade da terra urbana}

Em pesquisas mais recentes se tem observado que a irregularidade da propriedade ultrapassa em muito apenas as áreas subnormais ou de favelas e mesmo os assentamentos irregulares e periféricos (Ávila \& Ferreira, 2016; Ferreira \& Ávila, 2018). Muitas áreas e bairros, em grandes cidades, que inclusive são caracterizados por padróes construtivos e urbanísticos elevados, também apresentam irregularidades quanto à propriedade da terra ou à falta da existência efetiva de títulos/documentos registrados que atestem esse aspecto.

Por sua vez, na sociedade brasileira, existem relaçóes distintas entre os conceitos de "propriedade do título" e a "posse" da habitação e da terra onde ela está localizada. Dessa maneira, também ocorrem diferenças nas percepçóes dos agentes quanto à insegurança da posse. De acordo com Fernandes (2011):

A key aspect of informality is the lack of de jure or formal title, although many urban residents feel secure with de facto property rights of ownership based on customary practices. Residents in informal settlements developed on private land often have bills of sale or related documents, and these properties are bought and sold regularly (p. 2).

Muitas famílias que possuem efetivamente a posse de seus domicílios não possuem necessariamente o título regular de propriedade da terra. Gerando uma enorme confusão conceitual, sobre o que, de fato, é propriedade, posse e direito à habitação. Nesse sentido, Taylor (2006) citado por Moroni (2018), observa que:

We can agree with Hospers (2007: 61) that the right to property is without doubt the most misunderstood of basic rights. Even John Rawls - the most important political philosopher of the twentieth century and one of the most influential thinkers also in the policy and planning literature - devotes only brief and ambiguous discussion to the matter (Taylor, 2006 citado por Moroni, 2018, p. 274).

Moroni(2018), por sua vez, acrescenta que:

One aspect in particular seems to have created confusion also in the debate on land use policies and planning practices: that is, the confusion between the general right to hold private property and specific property titles (in part this is due to the fact that the term 'rights' is often used interchangeably in both cases, just as are analogous terms in other languages) ( p. 274). 
De qualquer maneira, o fato de não possuir um título de propriedade ou esse título não estar em situação regular, isso pode causar uma série de problemas e constrangimentos às famílias. Entre outras consequências se tem questôes relacionadas à subvalorizarão do imóvel, dificuldades na obtenção de empréstimos junto a bancos, dificuldades em acessar os tribunais e à justiça, o imóvel não poder participar de programas habitacionais oficiais, impedimentos para fazer hipotecas, problemas relacionados a heranças e quando for o caso, problemas envolvendo desapropriaçôes. Também, em muitas situaçóes, principalmente em áreas de mais baixa renda, o próprio poder público se recusa a fornecer infraestrutura (lazer, pavimentação de ruas, saneamento, etc.) e também serviços (segurança, coleta de lixo, iluminação, entre outros) em função da região ser "ilegal".

Da mesma maneira, a "irregularidade da propriedade da terra" também pode estar correlacionada a ameaças a integridade e à inviolabilidade dos domicílios (crimes relacionados às invasóes dos domicílios por pessoas estranhas, arrombamentos, expulsões pelo tráfico de drogas, expulsóes compulsórias pelo próprio poder público, etc.).

Mesmo considerando todos esses aspectos, observa-se que no Brasil, as relaçôes entre a "irregularidade" dos títulos de propriedade, da efetiva ou não "posse" da terra e a "criminalidade", especialmente a mais dirigida à habitação propriamente dita, ainda são muito pouco analisadas e estudadas.

Dessa forma, parte-se da ideia de que, domicílios que apresentem irregularidade na propriedade da terra, onde estáo construídos, estariam mais sujeitos à insegurança na manutenção desse patrimônio, vis a vis os domicílios que possuem direitos de propriedade regularizados. Nesse caso, os crimes poderiam ocorrer nesses domicílios em função de vários motivos. No entanto, especificamente, áreas irregulares muitas vezes, tem problemas quanto a infraestrutura urbana, iluminação, casas abandonadas, falta de serviços entre eles de policiamento, além do que, os domicílios com propriedade irregular têm maiores dificuldades em acionar a própria justiça.

\section{Criminalidade e o espaço metropolitano}

São muitas as teorias que procuram explicar a criminalidade e principalmente a violência, seja sob um ponto de vista mais social, seja sobre uma abordagem mais individual. De qualquer maneira, tudo indica que os mais variados aspectos acabam concorrendo para a existência desse tipo de fenômeno. Assim, de acordo com Dalbergh \& Krug (2007): "Não há um fator único que explique por que alguns indivíduos se comportam violentamente com outros ou por que a violência é mais comum em algumas comunidades do que em outras. A violência é o resultado da complexa interação dos fatores individuais, relacionais, sociais, culturais e ambientais" (Dalbergh \& Krug, 2007, p. 1172).

Porém ao lidar especificamente com crimes relacionados aos domicílios ou mais especificamente à habitação, objeto que está estritamente vinculado ao espaço em que ocupa, as vertentes teóricas que procuram incluir abordagens de caráter comunitário e urbanístico sobre sua influência no crime e na violência passam a ser importantes. No entanto, nesse contexto, deve-se ressalvar que, pelo menos até o momento 
na literatura, parece que muito pouco foi analisado quanto as relaçóes entre a posse e a propriedade efetiva ou não da terra urbana e sua relação com a violência, especialmente na América Latina. Mesmo porque, a disponibilidade de dados confiáveis que convirjam para ambas as questôes, ainda é, relativamente, bem restrita.

De fato, existe um grande número de estudos que procura relacionar o processo de urbanização, de industrialização e de marginalização de populaçóes com o aumento da criminalidade. Vale mencionar, os trabalhos seminais de Robert Park e Ralph Turner já no início do século xx, analisando a organização sócio espacial da cidade de Chicago, nos Estados Unidos (Park \& Turner, 1967; Santos, 2016).

No que se refere à estruturação do espaço intraurbano ou dos determinantes da localização residencial, a chamada Escola de Chicago desenvolveu alguns paradigmas que podem auxiliar no entendimento das dinâmicas envolvendo a irregularidade da posse da terra. Nesse contexto, Farret (1985) pontua que:

... a tradição da "Escola de Chicago de Ecologia Humana", os modelos ecológicos enfatizam o processo de competição entre os vários segmentos da população urbana, a dominação de cada segmento em suas respectivas áreas "naturais" dentro da cidade e a invasão destas áreas por grupos concorrentes, culminando com a sucessão de um novo grupo em posição de dominância, reiniciando, portanto, o processo geral. O indivíduo não teria outra ação locacional que não fosse a "acomodação" a uma determinada parte do espaço urbano (p.76).

Essa Escola também lançou as bases para o que viria a ser caracterizado como teorias ecológicas do crime, que vinculavam a ocorrência de determinados tipos de comportamento social ao local ou à paisagem, ondem eles ocorriam. De acordo com Santos (2016) citado por Cerqueira (2017, p. 27) as variáveis ou fatores explicativos nessa perspectiva estariam mais relacionados a: Status socioeconômico, etnia, mobilidade social, desestruturação familiar, processo de urbanização, redes sociais, desemprego, densidade populacional, participação em instituiçôes (igrejas, sindicados, etc.).

Considerando esses contextos, Andrade, Peixoto e Moro (2003), analisam que:

A explicação ecológica do crime passa por duas vertentes, as teorias de desordem física e de desordem social. A primeira relaciona o crime às características físicas das localidades, como prédios degradados, lotes vagos, etc., (Wilson \& Kelling, 1982). A desorganização social se refere à incapacidade da comunidade de integrar valores comuns de seus residentes e manter um efetivo controle social (Shaw \& Mckay, 1942; Sampson \& Grove, 1989) (p. 4).

Especificamente, quanto à integração social Andrade et al. (2003), observam que:

... a desorganizaçấo social, ou o seu oposto, a organização social, está calcada na capacidade da comunidade em supervisionar e controlar seus membros. Esse controle é exercido através de organizaçóes sociais formais, como por exemplo, associaçóes de bairros e religiosas ou através de outras formas de interação entre seus moradores. Assim, comunidades em que a população participa de comitês, clubes, instituições locais e outras organizaçôes tendem a ter menores taxas de criminalidades em relação às demais (pp. 4-5). 
É interessante observar que as dinâmicas envolvidas no processo de expansão urbana no Brasil e consequentemente de irregularidade da posse da terra urbana envolvem características importantes analisadas por esses paradigmas teóricos. As áreas mais recentemente ocupadas nas periferias, pelas populaçóes muito carentes (ou que não possuem condiçóes de habitar outras áreas na cidade) sem a titularidade da terra que ocupam, e sem acesso aos serviços urbanos básicos, estariam, pelo menos num primeiro momento, mais sujeitas a uma coesão social baixa, (entre outros motivos pela grande quantidade de pessoas entrando e saindo e consequentemente a construção de novos domicílios) além de apresentarem desordem física. Estando assim, mais passíveis à criminalidade e a terem relaçóes de posse da terra mais frágeis (ou seja, estando sujeitas a expulsôes a invasôes e outros tipos de violência). Nesse contexto, Dalbergh e Krug (2007) observam que:

Um alto nível de mobilidade residencial (em que as pessoas não permanecem por muito tempo numa mesma residência, mas se mudam com frequência), heterogeneidade (população altamente diversificada, com pouco do adesivo social que mantém as comunidades unidas) e alta densidade populacional são exemplos daquelas características, e cada uma delas tem sido associada a violência (p. 1.173).

Considerando esses aspectos, uma possibilidade contrária seria que, nas áreas onde, mesmo ocorrendo irregularidade da titulação, porém com maior coesão social haveria menos crimes e a posse da terra seria mais consolidada. Nesse caso, a própria organização social também poderia ser um fator que permitiria a garantia da posse da terra, independentemente de sua titularidade.

De acordo com Glaeser (2016),

... a taxa de criminalidade geral em Mumbai é muito menor do que na Índia urbana como um todo. As favelas de Mumbai não dão a sensaçấo de perigo que senti nas favelas do Rio ou nas regióes mais pobres de Nova York nos anos 1970. Essa discrepância não é porque a polícia de Mumbai esteja fazendo um bom trabalho e Mumbai é mais pobre do que o Rio.

A melhor explicação para a segurança das favelas de Mumbai é que, embora esses lugares sejam pobres, eles também são espaços sociais que funcionam bem, como Greenwhich Village descrito por Jane Jacobs em sua obra-prima Morte e vida das grandes cidades de 50 anos atrás. Nessas áreas, os residentes observam as ruas e becos. O mau comportamento é rapidamente notado e abordado, não pela polícia, mas pela comunidade (p. 106).

Essas situações seriam representadas pelas comunidades, favelas e ocupaçôes, que social e espacialmente já estão reconhecidas por todos os moradores da cidade. Normalmente, são áreas de ocupaçóes mais antigas que possuem uma dinâmica urbana própria. Por outro lado, empiricamente no Brasil, se tem observado que, áreas ou as cidades mais ricas, que "concentram" a infraestrutura, os empregos e a riqueza, também atrairiam crimes, principalmente contra o patrimônio. Nesse caso, Beato (1998) observa, num estudo sobre os determinantes da criminalidade, especificamente, no estado de Minas Gerais que, a densidade populacional e a riqueza também atraem a violência. Nesse sentido, as elevadas concentraçóes humanas nas 
cidades permitem uma maior impessoalidade de seus habitantes e com isso um maior anonimato e privacidade de seus habitantes, inclusive dos criminosos. Assim, de acordo com esse autor:

Ao contrário do proposto em pilhas de produção intelectual e pesquisa sistemática, a correlação a ser estabelecida para a explicação do crime não é com a pobreza, mas com a riqueza. Isto porque a prosperidade termina por ensejar um incremento nas oportunidades para a ação criminosa, na medida em que fornece alvos viáveis e compensadores, bem como dificulta os mecanismos tradicionais de controle social e vigilância (p. 7).

Corroborando essa perspectiva, Beato e Reis (2000) concluem que "no caso dos municípios do estado de Minas Gerais, observa-se claramente um padrão e distribuição de criminalidade violenta, especialmente o crime contra o patrimônio, que se distribui em torno das regióes e cidades mais desenvolvidas" (p. 11).

De qualquer maneira, vale observar que, as cidades e regióes mais prósperas, em qualquer lugar do mundo, tendem a concentrar mais população e renda. Nesse sentido, Glaeser (2016) observa que:

As taxas de criminalidade têm apresentado boa correlaçáo com o tamanho da cidade, mas as diferenças dessas taxas entre cidades e ao longo do tempo têm pouco a ver com a aplicação da lei, rendimento ou outro aspecto que possa ser mensurado (p. 106).

Tudo isso pode ensejar, de uma forma ou de outra, pelo menos, uma vinculação complexa entre uma dinâmica própria da ocupação e da concentração da riqueza no espaço metropolitano, a regularidade ou a irregularidade da posse da terra e a dinâmica da criminalidade, que serão analisadas mais detalhadamente no capítulo seguinte.

\section{Evidências empíricas: as variáveis}

Uma característica fundamental, com relação aos dados utilizados é que todos fazem parte de um mesmo banco de dados, produzidos em uma única pesquisa. Essas informaçóes foram coletadas de forma inédita no Brasil a partir da Pesquisa por Amostra de Domicílios de Minas Gerais (PAD), ${ }^{1}$ que tem com período de referência o mês de setembro do ano de 2013.

Com uma amostra de aproximadamente 18.000 domicílios, a PAD-MG é significativa para todo o Estado de Minas Gerais, suas Mesorregióes geográficas, para a Região Metropolitana de Belo Horizonte (RMBH) e especificamente para o município de Belo Horizonte.

Isso permitiu a realização de comparações entre as variáveis analisadas, relativas aos domicílios que se localizavam no município de Belo Horizonte e nos demais domicílios localizados no restante da regiáo metropolitana.

1 A PAD-MG, foi inicialmente desenvolvida a partir de uma parceria entre o Banco Mundial (World Bank) e a Fundação João Pinheiro, para a obtenção de dados destinados à avaliação de políticas públicas no Estado de Minas Gerais. 
Assim, nos próximos itens, serão explicitados como as variáveis da irregularidade da posse ou da propriedade da terra e sobre invasáo e ou arrombamento de domicílios foram construídas, suas definições, suas limitações e suas frequências.

\section{Irregularidade da propriedade urbana}

Para a definição do que seria a irregularidade da propriedade da terra urbana, a partir do total de domicílios da Pesquisa por Amostra de Domicílios de Minas Gerais - 2013, incialmente foram selecionados os domicílios permanentes individuais $^{2}$ urbanos da RMBH. Desse conjunto de domicílios, foram retirados da análise, os domicílios considerados "náo próprios", ou seja, os alugados, os cedidos e os que apresentavam outras condiçóes (tabela 3). Nesses casos, foi considerado que os ocupantes dos imóveis náo teriam conhecimento da real regularidade da propriedade, na medida em que eram apenas usuários do imóvel. ${ }^{3}$

Os domicílios próprios, calculados da maneira descrita acima, representavam aproximadamente, 69\% do total de domicílios na Região Metropolitana de Belo Horizonte. Sendo que, especificamente, na capital metropolitana, Belo Horizonte, essa proporção era de aproximadamente $63 \%$ do total de domicílios.

A partir desses domicílios próprios, a irregularidade da propriedade da terra urbana foi calculada da seguinte maneira:

Inicialmente, foi perguntado se os terrenos dos domicílios próprios também eram próprios. No caso, do terreno ser não próprio foi perguntado se estava localizado em área pública, área de proteção ambiental ou mesmo área privada de terceiros.

Sendo as propriedades consideradas como próprias foi inquirido qual era a real situação de titulação e de registro dos terrenos identificados como próprios.

TABELA 3 | Região Metropolitana de Belo Horizonte - Condição do domicílio 2013

\begin{tabular}{|c|c|c|c|c|c|c|}
\hline DOMICÍlLIO & BH & $\%$ & OUTROS* & $\%$ & RMBH & $\%$ \\
\hline Alugado & 215.066 & 24,23 & 177.054 & 17,88 & 392.120 & 20,88 \\
\hline Próprio - já pago & 523.518 & 58,98 & 704.951 & 71,21 & 1.228 .469 & 65,43 \\
\hline Próprio - pagando & 34.587 & 3,90 & 44.277 & 4,47 & 78.864 & 4,20 \\
\hline Cedido empregador & 1.539 & 0,17 & 2.601 & 0,26 & 4.140 & 0,22 \\
\hline Cedido outros & 102.222 & 11,52 & 57.173 & 5,77 & 159.395 & 8,49 \\
\hline Outra condição & 10.650 & 1,20 & 3.939 & 0,40 & 14.589 & 0,77 \\
\hline Total & 887.582 & 100 & 989.995 & 100 & 1.877 .577 & 100 \\
\hline \multicolumn{7}{|c|}{$\begin{array}{l}\text { * DEMAIS MUNICÍPIOS DA REGIÃO METROPOLITANA DE BELO HORIZONTE, EXCLUINDO-SE BELO } \\
\text { HORIZONTE }\end{array}$} \\
\hline \multicolumn{7}{|l|}{ FONTE } \\
\hline
\end{tabular}

O entrevistado identificava qual o tipo de documento que estava em seu poder, se um título pleno de propriedade, de concessão de uso, uma promessa de compra e

2 Sendo assim, foram excluídos os domicílios coletivos (quarteis, conventos, etc.) e os improvisados (domicílios em pontes, praças, cavernas, etc.).

3 Considerando esse aspecto pode haver uma subestimativa do total de domicílios com irregularidade da posse. 
venda, um título de legitimação de posse, e se esses documentos estavam registrados em algum tipo de cartório. Finalmente, a pesquisa quis saber se os documentos emitidos foram registrados, especificamente, nos cartórios de imóveis.

Considerando a soma dos domicílios próprios urbanos sem terreno próprio (por exemplo, ocupaçóes recentes de áreas privadas, áreas públicas, áreas de preservação ambiental etc.) sem documentação de titulação da terra ou com documento, porém sem registro dos títulos existentes (em cartório de imóveis), chega-se ao número total de domicílios com insegurança da posse (Ávila \& Ferreira, 2016, pp. 7-8).

Dessa maneira, estimou-se que 22,3\% de domicílios próprios urbanos da $\mathrm{RMBH}$ apresentavam irregularidade da posse. Especificamente, para o município de Belo Horizonte foi calculado $27,6 \%$ dos domicílios próprios, e para o restante dos municípios metropolitanos $18,3 \%$ dos domicílios.

TABELA 4 Região Metropolitana de Belo Horizonte-Domicílios urbanos próprios

\begin{tabular}{|l|c|c|c|}
\hline \multicolumn{4}{|c|}{ SEGURANÇA DA POSSE X INSEGURANÇA DA POSSE } \\
\hline \multirow{2}{*}{ LOCAL } & INSEGURANÇA & SEM INSEGURANÇA & TOTAL \\
\hline \multirow{2}{*}{ BH } & 138.377 & 362.097 & 500.474 \\
& $27,6 \%$ & $72,4 \%$ & $100 \%$ \\
\hline Outros* & 119.231 & 533.886 & 653.117 \\
& $18,3 \%$ & $81,7 \%$ & $100,0 \%$ \\
\hline RMBH & 257.608 & 895.983 & 1.153 .591 \\
& $22,3 \%$ & $77,7 \%$ & $100 \%$ \\
\hline
\end{tabular}

* Demais municípios da REgião METropolitana de belo horizonte, EXCLUINDO-SE BELO

FONTE ELABORAÇÃO PRÓPRIA COM BASE EM FJP (2OI 4)

Chama atenção a elevada proporção da irregularidade da propriedade no município de Belo Horizonte, que normalmente concentra, quase metade da população metropolitana. Dois aspectos estariam relacionados a isso: A alta concentração de domicílios em áreas subnormais (favelas) e também a existência de irregularidade da posse junto a domicílios localizados mesmo em áreas de maior renda média.

\section{Arrombamentos e ou invasóes}

Nessa análise, procurou-se focar os crimes contra o patrimônio, relacionados ao arrombamento e ou invasão de domicílios. Logicamente, esse tipo de ocorrência está diretamente vinculado à habitação e à sua localização.

No caso das informaçóes sobre esses crimes, foram utilizados os dados sobre vitimização desenvolvidas e coletados pela Pesquisa por Amostra de Domicílios de Minas Gerais (PAD) 2013. Nesse caso, de acordo com o Boletim PAD; (FJP, 2015):

Pesquisas de vitimização são realizadas a partir de entrevistas feitas diretamente com uma dada população. Ou seja, pergunta-se diretamente aos indivíduos, se já foram vítimas de crimes, em quais circunstâncias ocorreram como hora, local, uso de armas, consequências econômicas, qual o perfil de vítimas e agressores, qual o relacionamento estabelecido entre eles, quando for o caso. (FJP, 2015, p. 10)

Na PAD-2013, especificamente, o quesito ou a pergunta sobre invasão de domicílios foi: "Nos últimos 12 meses, quantas vezes o domicílio foi arrombado ou invadido? 
(Tendo ocorrido ou não furto e/ou roubo durante a invasão)" (FJP, 2014). Nesse caso, deve-se enfatizar que, mesmo estando o roubo e o furto entre causas mais frequentes para a invasão/arrombamento dos domicílios, esses não são os únicos motivos. Podem existir outras possibilidades, como despejos forçados (realizados, por exemplo, pela polícia, traficantes e mesmo parentes), violência doméstica, uso de narcóticos, vandalismos, entre outros.

Assim, em relação ao "total" de domicílios urbanos da capital Belo Horizonte, (incluindo-se nesse caso, os alugados, cedidos, etc.) 2,21\% foram alguma vez, invadidos nos doze meses que precederam a data de referência da pesquisa.

$\mathrm{Na}$ tabela 5, se focarmos os domicílios urbanos localizados nos demais/outros municípios da $\mathrm{RMBH}$, essa proporção é de 2,66\%, ou seja, um porcentual ligeiramente superior ao observado em Belo Horizonte.

TABELA 5 | Frequência de invasóes e ou arrombamentos domicílios urbanos (“todos” os domicílios incluindo alugados, cedidos, etc.) - Regiáo Metropolitana de Belo Horizonte

\begin{tabular}{|c|c|c|c|c|c|c|}
\hline \multirow[b]{2}{*}{ LOCAL } & \multirow{2}{*}{$\begin{array}{c}\text { NÃO FOI } \\
\text { (A) }\end{array}$} & \multicolumn{5}{|c|}{$\begin{array}{c}\text { NOS ÚLTIMOS I2 MESES, ¿QUANTAS VEZES O DOMICÍLIO FOI } \\
\text { ARROMBADO OU INVADIDO? (TENDO OCORRIDO OU NÃO FURTO E/ } \\
\text { OU ROUBO DURANTE A INVASÃO) }\end{array}$} \\
\hline & & I VEZ (B) & 2 VEZES $(c)$ & $\begin{array}{l}3 \text { VEZES } \\
\text { E }+(D)\end{array}$ & \begin{tabular}{|c|} 
TOTAL \\
ALGUMA VEZ \\
INVADIDO \\
$(\mathrm{B}+\mathrm{C}+\mathrm{D})$ \\
\end{tabular} & $\begin{array}{c}\text { TOTAL } \\
(\mathbf{A}+\mathbf{B}+\mathbf{C}+\mathbf{D})\end{array}$ \\
\hline $\mathrm{BH}$ & 864.435 & 14.741 & 668 & 4.158 & 19.567 & 884.002 \\
\hline$\%$ & $97,79 \%$ & $1,65 \%$ & $0,08 \%$ & $0,46 \%$ & $2,21 \%$ & $100 \%$ \\
\hline Outros* & 951.094 & 23.325 & 2.399 & 295 & 26.019 & 977.113 \\
\hline$\%$ & $97,34 \%$ & $2,39 \%$ & $0,25 \%$ & $0,03 \%$ & $2,66 \%$ & $100 \%$ \\
\hline Total RMBH & 1.815 .529 & 38.066 & 3.067 & 4.453 & 45.586 & 1.861 .115 \\
\hline$\%$ & $97,55 \%$ & $2,05 \%$ & $0,16 \%$ & $0,24 \%$ & $2,45 \%$ & $100 \%$ \\
\hline \\
\hline FONTE & DRAÇÃO PRĆ & RIA COM BASE & EM FJP (2OI4) & & & \\
\hline
\end{tabular}

É interessante observar que também foram obtidos dados da frequência com que os domicílios foram invadidos/arrombados. Nesse aspecto, Belo Horizonte apresenta a maior frequência de domicílios que foram arrombados três ou mais vezes no último ano. Enquanto os demais domicílios urbanos, localizados no restante da região metropolitana apresentam maior frequência entre uma e duas vezes.

De qualquer maneira, a variável que será utilizada, neste trabalho é se o domicilio foi arrombado e ou invadido ou náo (representado, pela coluna "Total alguma vez invadido"), a frequência com que isso ocorreu não foi levada em consideração. No entanto, esse aspecto, é relevante e merece ser analisado em estudos futuros. 


\section{Irregularidade da propriedade, arrombamentos de domicílios e espaço metropolitano}

Considerando as variáveis descritas anteriormente, procurou-se realizar os cruzamentos entre domicílios com irregularidade da propriedade do solo urbano (conforme calculado), o fato do domicilio ter sido arrombado ou não, e o fato de estar localizado no município sede da região metropolitana, Belo Horizonte, ou nos outros municípios dessa região (tabela 6 - Tabela de contingência).

Nesse sentido, foi realizada uma análise Loglinear. Esse procedimento é particularmente útil quando se trabalha com análises de associação entre mais de duas variáveis categóricas, como é o caso em análise. (Powers \& Xie, 2008), (Field, 2018).

Inicialmente, são apresentados a tabela com os cruzamentos das três variáveis:

- Domicílio localizado em Belo Horizonte (вн) ou não (Fora de вн).

- Insegurança da Posse (INSEPOss), no caso com segurança (SEG) ou não (INSEg)

- Domicílio invadido e ou arrombado (ARro) nos últimos 12 meses: (Aconteceu e Não Aconteceu).

$\mathrm{Na}$ tabela 6 também estão incluídos os valores porcentuais das linhas (\% SEG) e das colunas (\% ARRO). Os valores acumulados são representados por (\%TSEg e \%TARRO) Além, das estimativas dos valores esperados (V. Esperado).

É interessante observar, que os domicílios urbanos, fora da capital Belo Horizonte, que possuem insegurança da posse, apresentam uma maior frequência de arrombamentos, do que os domicílios localizados nessas mesmas áreas, porém que apresentam segurança.

No caso específico do município de Belo Horizonte, essa situação se inverte, ou seja, os domicílios com segurança na titulaçáo de terras apresentam uma frequência maior de casos de arrombamentos, vis a vis os com insegurança ou que não estejam formalmente titulados.

$\mathrm{Na}$ Figura 1 da mesma forma estão representadas as distribuiçôes totais porcentuais dos domicílios urbanos por localização (Total de Domicílios fora de BH e Total de Domicílios em вн), se os domicílios foram arrombados ou não nos últimos doze meses (Aconteceu e Não Aconteceu) e se possuem ou não a segurança da propriedade (Segurança x Insegurança).

Nesse gráfico fica claro, principalmente no que se refere ao município de Belo Horizonte, o fato, da distribuição porcentual dos domicílios com segurança da posse $(69,18 \%)$ ser menor do que a frequência observada nos domicílios nos outros municípios da RMBH $(79,37 \%)$, sendo, que no primeiro caso, 3,08\% foram arrombados, e no segundo, $2,11 \%$. 
TABEla 6 | Tabela de contingência-Domicílios próprios urbanos - RMBH

\begin{tabular}{|c|c|c|c|c|}
\hline \multirow[t]{2}{*}{ LOCAL } & \multirow{2}{*}{$\begin{array}{l}\text { SEGURANÇA DA } \\
\text { POSSE }\end{array}$} & \multicolumn{3}{|c|}{$\begin{array}{l}\text { NOS ÚLTIMOS I } 2 \text { MESES, O DOMICÍLIO FOI } \\
\text { ARROMBADO E OU INVADIDO? }\end{array}$} \\
\hline & & NÁO ACONTECEU & ACONTECEU & TOTAL \\
\hline \multirow{12}{*}{ Fora de $\mathrm{BH}$} & SEG & 508.585 & 13.516 & 522.101 \\
\hline & $\%$ SEG & $97,4 \%$ & $2,6 \%$ & $100 \%$ \\
\hline & $\%$ ARRO & $81,7 \%$ & $75,4 \%$ & $81,5 \%$ \\
\hline & V. Esperado & $507.487,4$ & $14.613,6$ & 522.101 \\
\hline & INSEG & 114.247 & 4.419 & 118.666 \\
\hline & $\%$ INSEG & $96,3 \%$ & $3,7 \%$ & $100 \%$ \\
\hline & $\%$ ARRO & $18,3 \%$ & $24,6 \%$ & $18,5 \%$ \\
\hline & V. Esperado & $115.344,6$ & $3.321,4$ & 118.666 \\
\hline & Total & 622.832 & 17.935 & 640.767 \\
\hline & $\%$ TSEG & $97,2 \%$ & $2,8 \%$ & $100 \%$ \\
\hline & $\%$ TARRO & $100,0 \%$ & $100,0 \%$ & $100 \%$ \\
\hline & V. Esperado & $622.832,0$ & $17.935,0$ & 640.767 \\
\hline \multirow{12}{*}{$\mathrm{BH}$} & SEG & 344.815 & 15.353 & 360.168 \\
\hline & $\%$ SEG & $95,7 \%$ & $4,3 \%$ & $100 \%$ \\
\hline & $\%$ ARRO & $71,5 \%$ & $93,4 \%$ & 72,2 \\
\hline & V. Esperado & $348.291,1$ & $11.876,9$ & 360.168 \\
\hline & INSEG & 137.290 & 1.087 & 138.377 \\
\hline & $\%$ INSEG & $99,2 \%$ &, $8 \%$ & $100 \%$ \\
\hline & $\%$ ARRO & $28,5 \%$ & $6,6 \%$ & $27,8 \%$ \\
\hline & V. Esperado & $133.813,9$ & $4.563,1$ & $138.377,0$ \\
\hline & Total & 482.105 & 16440 & 498.545 \\
\hline & $\%$ TSEG & $96,7 \%$ & $3,3 \%$ & $100 \%$ \\
\hline & $\%$ TARRO & $100,0 \%$ & $100,0 \%$ & $100 \%$ \\
\hline & V. Esperado & $482.105,0$ & $16.440,0$ & 498.545 \\
\hline \multirow{12}{*}{ Total } & SEG & 853.400 & 28.869 & 882.269 \\
\hline & $\%$ SEG & $96,7 \%$ & $3,3 \%$ & $100 \%$ \\
\hline & $\%$ ARRO & $77,2 \%$ & $84,0 \%$ & $77,4 \%$ \\
\hline & V. Esperado & $855.649,4$ & $26.619,6$ & 882.269 \\
\hline & INSEG & 251.537 & 5.506 & 257.043 \\
\hline & $\%$ INSEG & $97,9 \%$ & $2,1 \%$ & $100 \%$ \\
\hline & $\%$ ARRO & $22,8 \%$ & $16,0 \%$ & $22,6 \%$ \\
\hline & V. Esperado & $249.287,6$ & $7.755,4$ & 257.043 \\
\hline & Total & 1.104 .937 & 34.375 & 1.139 .312 \\
\hline & $\%$ TSEG & $97,0 \%$ & $3,0 \%$ & $100 \%$ \\
\hline & $\%$ TARRO & $100,0 \%$ & $100,0 \%$ & $100 \%$ \\
\hline & V. Esperado & $1.104 .937,0$ & $34.375,0$ & $1.139 .312,0$ \\
\hline
\end{tabular}

FONTE ELABORAÇÃo PRÓPRIA 


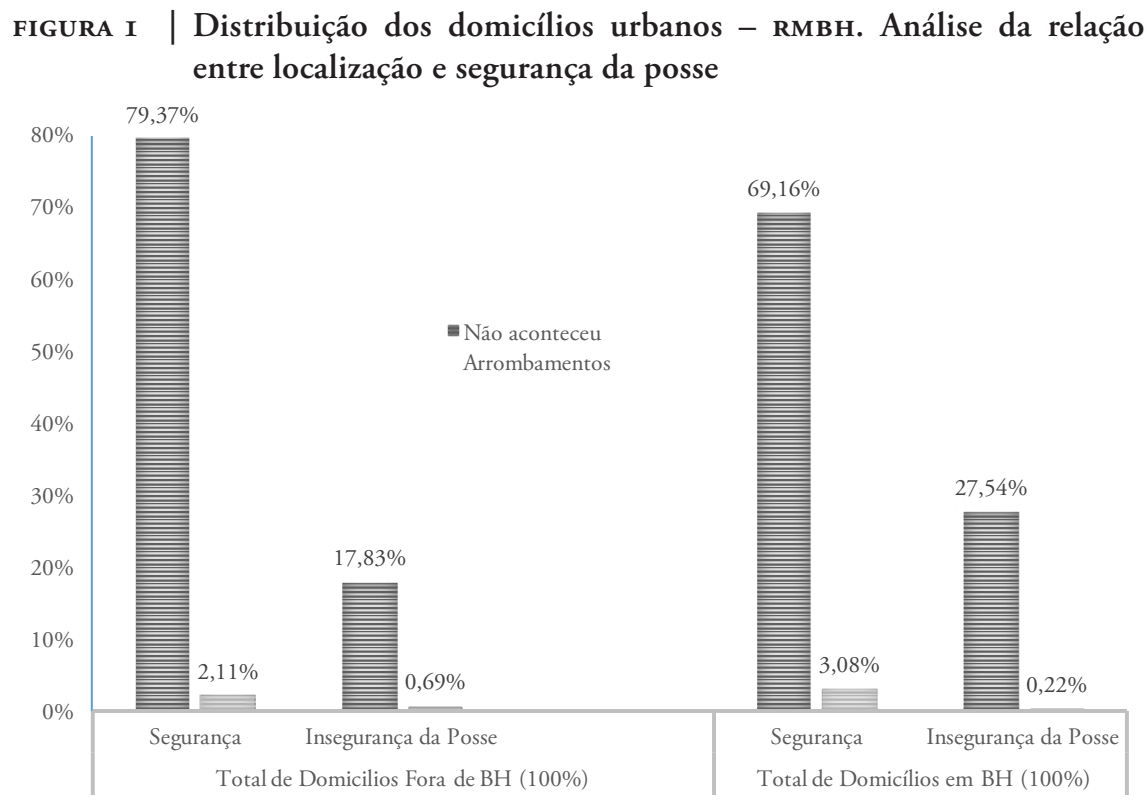

FONTE ELABORAÇÃo PRÓPRIA

\section{Os modelos}

Os modelos Loglineares descrevem padróes de associação e interação entre um número determinado de variáveis categóricas. Nesse tipo de análise, ao final, não se distinguem as variáveis entre explanatórias e dependentes.

Essa técnica, que é relativamente simples, mas que fornece resultados robustos, consiste na linearização de uma função logarítmica que procura estimar as frequências esperadas das variáveis categóricas envolvidas no modelo. Esse procedimento também possui um caráter hierárquico, no sentido em que, vários modelos são processados ao mesmo tempo e o que apresenta a melhor associação entre as variáveis, em análise, deve ser o escolhido (Powers \& Xie, 2008).

Dessa maneira, procurou-se proceder a análise Loglinear da tabela de contingência elaborada (tabela 6).

Os modelos estimados apresentaram um bom ajuste em relação aos dados. $\mathrm{Na}$ tabela de efeitos de ordem mais alta e K-ways (tabela 7) podemos observar que se removermos quaisquer tipos de associação entre as variáveis, sejam elas de primeira ordem (independência condicional $\mathrm{P}=1$ ) $^{4}$ sejam de segunda ordem (dois a dois $\mathrm{P}=2)^{5}$, sejam o de terceira ordem ou saturado (associação entre as três variáveis $\mathrm{P}=3)^{6}$, isso poderá afetar, o ajuste geral. Dessa forma, pode-se concluir que as iteraçôes entre as três variáveis são capazes de prever de forma significativa os dados (sig < 0,05 para todos os modelos) (Field, 2018, p. 872).

$4 \quad$ Modelo de $\mathrm{x}$ e y independentes dado w (xy, $\mathrm{Yw})$.

5 Modelo de associação 2 a 2 (xy, xw, rw).

6 Modelo de terceira ordem - Saturado (xYw). 
TABELA 7 | Efeitos de ordem mais alta e K-Way

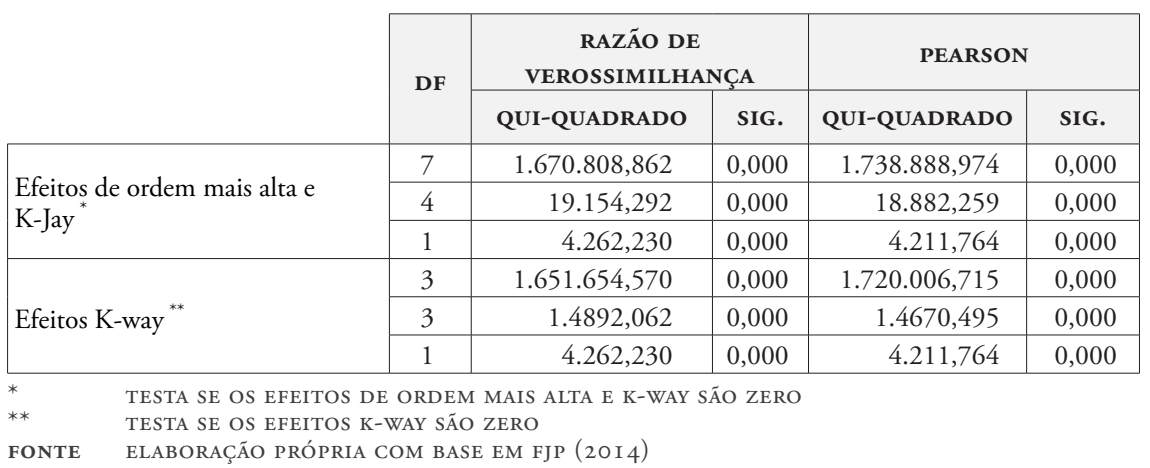

Sendo normalmente o modelo de maior hierarquia o escolhido, (no caso, o de terceira ordem ou saturado), foram estimados seus parâmetros (tabela 8).

TABELA 8 | Estimativas de parâmetro

\begin{tabular}{|c|c|c|c|c|c|c|c|}
\hline \multirow{2}{*}{ EFEITO } & \multirow{2}{*}{$\begin{array}{c}\text { PARÂ- } \\
\text { METRO }\end{array}$} & \multirow{2}{*}{$\begin{array}{l}\text { ESTIMA- } \\
\text { TIVA }\end{array}$} & \multirow{2}{*}{ ERRO } & \multirow{2}{*}{$\mathbf{Z}$} & \multirow{2}{*}{ SIG. } & \multicolumn{2}{|c|}{$\begin{array}{c}\text { INTERVALO DE } \\
\text { CONFIANÇA DE } 95 \%\end{array}$} \\
\hline & & & & & & $\begin{array}{c}\text { LIMITE } \\
\text { INFERIOR }\end{array}$ & $\begin{array}{l}\text { LIMITE } \\
\text { SUPERIOR }\end{array}$ \\
\hline BH*INSEPOSS*ARRO & 1 & 0,263 & 0,005 & 58,167 & 0,000 & 0,254 & 0,272 \\
\hline BH*INSEPOSS & 1 & $-0,120$ & 0,005 & $-26,489$ & 0,000 & $-0,129$ & $-0,111$ \\
\hline $\mathrm{BH}^{*}$ ARRO & 1 & $-0,134$ & 0,005 & $-29,605$ & 0,000 & $-0,143$ & $-0,125$ \\
\hline INSEPOSSE*ARRO & 1 & $-0,169$ & 0,005 & $-37,391$ & 0,000 & $-0,178$ & $-0,160$ \\
\hline $\mathrm{BH}$ & 1 & 0,185 & 0,005 & 40,945 & 0,000 & 0,176 & 0,194 \\
\hline INSEPOSS & 1 & 0,772 & 0,005 & 171,006 & 0,000 & 0,764 & 0,781 \\
\hline ARRO & 1 & 1,854 & 0,005 & 410,390 & 0,000 & 1,845 & 1,863 \\
\hline
\end{tabular}

FONTE ELABORAÇÃo PRÓPRIA COM BASE EN FJP (2OI4)

Por fim, o teste geral de adequação dos ajustes foi $\mathrm{x}^{2}(0)=0$ e $\mathrm{p}=1$ demonstrando que a associação de maior ordem (localização x insegurança da posse $\mathrm{x}$ arrombamentos) é significativa. (Field, 2018, p. 869). Também deve-se observar que os testes específicos do qui-quadrado para as variáveis analisadas duas a duas também foram significativos

\section{As razóes de chance}

Após os modelos serem avaliados, foram elaboradas as razóes de chance que, analiticamente, envolvessem mais os aspectos teóricos abordados.

Dessa maneira, inicialmente, foram calculadas a razão de chance de ocorrência (odds ratio) dos domicílios que estavam localizados na RMBH, porém fora do município de Belo Horizonte (fora de $\mathrm{BH}$ ), que apresentavam insegurança da posse e foram arrombados/invadidos em relação às chances de ocorrência dos domicílios 
que também estavam fora de BH, porém com segurança e foram arrombados/invadidos. A razão de chances (Odds Ratio) foi então obtida:

$$
\text { Odds Ratio }=\frac{\text { Odds,fora BH,insegurança da posse,arrombamento }}{\text { Odds,fora } \mathrm{BH}, \text { segurança da posse arrombamento }}=\frac{0,038679}{0,0265757}=1,45
$$

Assim, a chance de ocorrência de um domicílio urbano da Regiáo Metropolitana de Belo Horizonte, fora do município de Belo Horizonte, que tenha insegurança da posse e foi arrombado é 1,45 vezes maior que a chance de ocorrência de um domicilio urbano também localizado na Região Metropolitana de Belo Horizonte fora do município de Belo Horizonte, porém com segurança da posse e foi arrombado.

Procurou-se fazer essa análise agora para os domicílios localizados, especificamente no município de Belo Horizonte.

$$
\text { Odds Ratio }=\frac{\text { Odds,BH,segurança da posse,arrombamento }}{\text { Odds,BH,insegurança da posse arrombamento }}=\frac{0,044525}{0,0079175}=5,62
$$

Nesse caso, a chance de ocorrência de um domicílio urbano ${ }^{7}$ que esteja localizado, no município de Belo Horizonte, que tenha segurança da posse e foi arrombado é 5,62 vezes maior que a chance de ocorrência de um domicilio também localizado em Belo Horizonte, que tenha insegurança da titulação da terra e que foi arrombado/invadido.

\section{Conclusóes}

Os resultados obtidos a partir das razóes de chance analisadas são bastantes sugestivos. Quando analisamos os domicílios urbanos no município de Belo Horizonte e no restante da regiáo metropolitana, em relação à insegurança da propriedade da terra, tudo indica a ocorrência de uma inversão no que se refere a incidência de arrombamentos. As chances de invasão sáo maiores (por volta de 45\% maiores) nos demais municípios da região metropolitana quando os domicílios possuem insegurança da terra, em relação aos domicílios localizados nessas mesmas regióes, porém que possuem a documentação regular de sua habitação. Por sua vez, especificamente no município de Belo Horizonte, essas chances são bem maiores (mais de 400\% maiores) para aqueles que já possuem segurança da terra em relação àqueles que também se localizam na capital, porém com insegurança da posse do imóvel.

Um aspecto interessante, nesse caso, é que no município de Belo Horizonte, os domicílios urbanos irregulares quanto à posse da terra, são relativamente mais frequentes do que os domicílios com essa mesma característica, no restante da região metropolitana.

Tudo indica que, em áreas mais consolidadas, com maior acesso a bens e serviços públicos e menor desorganizaçáo social como no caso dos domicílios localizados no município de Belo Horizonte, a insegurança da propriedade da terra não estaria muito correlacionada com invasóes e arrombamentos de domicílios. Muito provavelmente, essas áreas já estão mais organizadas e em certa medida, a percepção da 
posse da terra é mais direta, o que, inclusive, pode gerar mecanismos de proteção contra esse tipo de violência.

Aqui, vale mencionar as observaçóes de Abramo (2012), voltadas para as questôes do próprio mercado informal de terras em favelas na América Latina, que logicamente envolve garantias de propriedade, inclusive que permitam sua transferência. Nesse caso, se desenvolvem relações sociais e instituiçôes não formais que, em última análise, permitem um certo nível de garantia da posse e da sua proteção:

El cimiento de esta institución informal del mercado no es de carácter legal, sino que depende de la permanencia en el tiempo de una forma particular de interdicción social la forma confianza-lealtad. Esta relación de reciprocidad interpersonal marca muchas relaciones sociales (Bruni, 2006) (Abramo, 2012, p. 42).

De acordo com essa perspectiva, uma possibilidade seria que, "mutatis mutandis", essas relaçóes sociais muitas vezes, caracterizadas como pessoais e de confiança (ou seja, que também acabam por envolver aspectos e redes de amizade, compadrio, familiares, etc.) poderiam se estender também, para a própria proteçáo dos imóveis contra invasóes.

Por outro lado, considerando-se os domicílios localizados na capital, o crime de invasão/arrombamento está mais correlacionado a domicílios com títulos de propriedade regulares ou consolidados. Nesse sentido, como descrito por Beato (1998) varáveis como riqueza, densidade e a impessoalidade ou o anonimato provavelmente poderiam ser mais determinantes na ocorrência desse tipo de ação em Belo Horizonte, que, no caso, é a maior cidade e concentra os bairros de mais alta renda da região metropolitana. Representando um chamariz para o comportamento criminoso.

Por sua vez, as outras áreas urbanas dos outros municípios da região metropolitana, onde ainda ocorrem fluxos populacionais mais significativos de pessoas carentes, e onde as ocupaçóes estão se constituindo ou não estão consolidadas, com maior desorganização urbanística e social, as análises demonstram uma correlação significativa entre insegurança da posse da terra e a ocorrência de arrombamentos a domicílios. Muito provavelmente, essas comunidades, como indicado pela revisão da literatura, possuem laços de coesão social fragilizados, menor integração entre a vizinhança e estão em processo de desenvolvimento de mecanismos de autoproteção, como provavelmente ocorreram, no passado, em áreas mais antigas e consolidadas da capital.

Muito provavelmente, políticas voltadas para a regularização fundiária, teriam impactos distintos nesses dois tipos de territórios. A segurança da posse da terra, especialmente em áreas mais periféricas e de ocupação mais recente, poderia ser determinante na maior segurança da posse e dessa maneira, provavelmente auxiliando na redução ou desestimulando a criminalidade que envolva invasóes de domicílios e expulsões forçadas.

Sem dúvida é necessário explorar mais os dados, desenvolver novos estudos, também sob uma perspectiva mais qualitativa, considerando a percepção dos moradores nas diferentes áreas quanto a relação da posse da terra versus violência e testar hipóteses, inclusive numa perspectiva de outros tipos de crimes. Nesse caso, por exemplo, não se sabe ao certo o impacto da insegurança da posse da terra, 
especialmente em áreas violentas dominadas, mais especificamente, pelo tráfico de drogas e ou por milicianos. De qualquer maneira, os resultados obtidos nesse trabalho podem ser um sólido ponto de partida.

Finalmente, pelo menos para a Região Metropolitana de Belo Horizonte, a segurança ou insegurança da posse da terra são dimensóes relevantes e estão diretamente correlacionadas com a violência relativa a invasão ou arrombamento de domicílios. Sendo que, esses dois aspectos (posse da terra e arrombamentos) também estão fortemente envolvidos com os diferentes processos de ocupação e consolidação dos espaços urbanos e a consequente criação de vínculos comunitários. Essa última dinâmica acaba por influenciar onde os crimes serão realizados.

\section{Referências bibliográficas}

Abramo, P. (2003). A cidade da informalidade: O desafio das cidades Latino-Americanas. Rio de Janeiro: Livraria Sette Letras/Faperj/Lincoln Institute.

Abramo, P. (2012). La ciudad com-fusa: mercado y producción de la estrutura urbana en las grandes metropoles latino-americanas. EURE, 38(114), 35-69. http://dx.doi. org/10.4067/S0250-71612012000200002

Andrade, M. V., Peixoto, B. T. \& Moro, S. (2003). Criminalidade na Região Metropolitana de Belo Horizonte: Uma Análise Espacial. Anais do XXV Encontro Brasileiro de Econometria. Porto Seguro, SBE. Em https://www.researchgate.net/profile/ Sueli_Moro/publication/4805373_CRIMINALIDADE_NA_REGIAO_ METROPOLITANA_DE_BELO_HORIZONTE_UMA_ANALISE_ESPACIAL/ links/02e7e51828fec63a34000000.pdf

Ávila, P. C. \& Ferreira, F. P. M. (2016). A insegurança da posse do solo urbano em Minas Gerais. URBE Revista Brasileira de Gestão Urbana, 8(2), 197-210. http://dx.doi. org/10.1590/2175-3369.008.002.ao03

Beato F. C. C. (1998). Determinantes da criminalidade em Minas Gerais. Revista Brasileira de Ciências Sociais, 13(37), 74-87. http://dx.doi.org/10.1590/S010269091998000200004

Beato C. \& Reis I. A. (2000). Desigualdade, desenvolvimento socioeconômico e crime [documento eletrônico]. Em https://www2.mppa.mp.br/sistemas/ gcsubsites/upload/60/DESIGUALDADE\%20DESENVOLVIMENTO\%20 S\%C3\%83\%E2\%80\%9CCIO\%20ECONOMICO\%20E\%20CRIME.pdf

Canettieri, T. (2014). A produção das novas periferias metropolitanas: Migração e expulsão dos pobres na rmbh na primeira década do século XXI (Dissertação de Mestrado). Pontifícia Universidade Católica de Minas Gerais (puc Minas). Em http://blog. indisciplinar.com/wp-content/uploads/2014/05/CANETTIERI-Thiago-AProdu\%C3\%A7\%C3\%A3o-das-Novas-Periferias-Metropolitanas.pdf

Cerqueira, D. (2007). Posições teóricas e metodológicas a propósito da violência e da criminalidade. Em C. Zanotelli, E. Raizer \& V. Valadão (eds.), Violência e contemporaneidade: dimensôes das pesquisas e impactos sociais (pp. 17-36). Vitória: Gráfica e Editora NEVI. 
Dalbergh, L. L. \& Krug, E. G. (2007). Violência: um problema global de saúde pública. Ciência \& Saúde Coletiva,11 (Sup), 1163-1178. http://dx.doi.org/10.1590/S141381232006000500007

Farret, R. L. (1985). Paradigmas da estruturação do espaço residencial intra-urbano. Em R. L. Farret (ed.), O espaço da Cidade: contribuição à análise urbana (pp. 73-90). Brasília: Projeto.

Fernandes, E. (2011). Regularization of informal settlements in latin America. Cambridge, MA: Lincoln Institute of Land Policy. Policy Focus Report. Em https://www.lincolninst. edu/sites/default/files/pubfiles/regularization-informal-settlements-latin-americafull_0.pdf

Ferreira, F. P. M. \& Ávila, Paulo C. (2018). Who has secure land tenure in the urban areas of Brazil? Evidence from the state of Minas Gerais. Land Use Policy, 75, 494-504. https:// doi.org/10.1016/j.landusepol.2018.03.054

Field, A. (2018). Discovering statistics using IBM-SPSS Statistics. (5th ed.). Brighton: Sage Edge.

Fundação João Pinheiro (FJP). (2014). Pesquisa por Amostra de Domicílios de Minas Gerais (PAD-MG). Boletim PAD-MG, 3(7), Belo Horizonte. Em http://www.fjp.mg.gov.br/index. $\mathrm{php/docman/cei/pad/502-boletim-pad-7-dezembro-19-11-2014-site-2/file}$

Fundação João Pinheiro (FJP) (2015). Pesquisa por Amostra de Domicílios de Minas Gerais (PAD-MG). Boletim pad Segurança Pública, 4(8), Belo Horizonte. Em http://fjp.mg.gov. br/index.php/docman/cei/pad/600-boletimpad8dezembro-10-12-2015-segurancapublica/file

Fundação João Pinheiro (fJP) (2016). Produto Interno Bruto dos Municípios de Minas Gerais 2010-2013: Nova série metodologia SNA/2008, Belo Horizonte. Em http://www.fjp. mg.gov.br/index.php/docman/cei/pib/pib-municipais/674-informativo-pib-dosmunicipios-2010-20142/file

Instituto Brasileiro de Geografia e Estatística (IBGE). (2010). Censo Demográfico, Rio de Janeiro. Em https://ww2.ibge.gov.br/home/estatistica/populacao/censo2010/default.shtm

Glaeser, E. (2016). O Triunfo da cidade. (2a ed.). São Paulo: BEI Ed.

Moroni, S. (2018). Property as a human right and property as a special title. Rediscussing private ownership of land. Land Use Policy, 70, 273-280. https://doi.org/10.1016/j. landusepol.2017.10.037

Park, R. E. \& Turner, R. H (eds.) (1967). On social control and collective behavior: Selected papers. Chicago, IL: University of Chicago Press, The Heritage of Sociology.

Powers, D. A. \& Xie, Y. (2008). Statistical Methods for Categorical Data Analysis (2a ed). Bingley, UK: Emerald Group Publishing.

Santos, M. A. F. (2016). Abordagens científicas sobre as causas da criminalidade violenta: Uma análise da Teoria da Ecologia Humana. Revista do Laboratório de Estudos da Violência UNESP, (17), 46-74. Em http://www2.marilia.unesp.br/revistas/index.php/levs/article/ view/5972/4010.

Souza, J. (2008). A expansão urbana de Belo Horizonte e da Região Metropolitana de Belo Horizonte: o caso específico do município de Ribeirão das Neves (Tese de Doutorado). Centro de Desenvolvimento e Planejamento Regional (Cedeplar)/ Universidade Federal de Minas Gerais (ufmG). Em http://www.bibliotecadigital.ufmg.br/dspace/ handle/1843/AMSA-7FNJKN?show=full

Villaça, F. (2001). O espaço intra-urbano. São Paulo: Studio Nobel Ed. 